\title{
CURSO DE FORMAÇÃO DE TUTORES NA ANP.NET: AMBIENTE VIRTUAL DE APRENDIZAGEM DA POLÍCIA FEDERAL.
}

\author{
Pablo Moreno Feitosa Gurgel \\ Polícia Federal, Mestre em Engenharia Urbana e Ambiental \\ e-mail: pablo.pmfg@dpf.gov.br \\ Maria Clara Silva Gurgel \\ Prefeitura Municipal de João Pessoa, Especialista em Supervisão e Orientação Educacional \\ e-mail: mclasgel@gmail.com
}

\begin{abstract}
RESUMO
O presente artigo apresenta o curso de formação de tutores de educação à distância da Polícia Federal. O curso é estruturado em ambiente virtual de aprendizagem. Os tutores atuam nas ações de capacitação executadas na plataforma virtual da instituição. Para a realização deste estudo foram feitas pesquisas em periódicos e sítios especializados, bem como na legislação relacionada ao objeto de estudo do artigo. Conclui-se neste estudo que o curso objetiva desenvolver competências relativas à atividade de tutoria em educação a distância na Polícia Federal, bem como compreender o processo educacional nesta modalidade e entender as funcionalidades do ambiente educacional ANP.net.
\end{abstract}

\section{ABSTRACT}

This article presents the course of tutors training of distance education of the Federal Police. The course is structured in a virtual learning environment. Tutors work in training activities performed on the virtual platform of the institution. For this study were made in research journals and specialized sites, as well as legislation related to the article object of study. It is concluded in this study that the course aims to develop skills related to tutoring activity in distance education in the Federal Police, as well as understanding the educational process in this mode and understand the features of the educational environment ANP.net.

\section{INTRODUÇÃO}

O presente artigo tem como tema curso de formação de tutores da Anp.Net: ambiente virtual de aprendizagem da Polícia Federal. Os ambientes virtuais de aprendizagem - AVA são espaços virtuais utilizados pelas esferas pública e privada para a capacitação de seus colaboradores em áreas do conhecimento que englobam as competências necessárias ao alcance dos objetivos institucionais. O termo AVA, também é conhecido como educação online, aprendizagem baseada em internet, e-learnig, Learning Management System (LMS) e consiste em um software baseado na Internet, no qual se disponibilizam os conteúdos, os recursos de interação e que permitem a facilitação da gestão de recursos virtuais. Existem diversos ambientes disponíveis no mercado, sejam eles de acesso livre (gratuitos) ou restrito (pagos).

Estes softwares possuem recursos e potencialidades, que os permitem ser estruturantes do currículo, pois, com essas características, segundo Almeida (2010, p. 92), "[...] as informações são representadas, organizadas e geridas, assim como são desenvolvidos os processos comunicativos e as produções individuais e em grupo". Os tutores, nestes casos, são responsáveis por saber utilizá-las para o alcance dos objetivos de cada curso. 
Almeida também declara que estes ambientes possuem algumas características importantes que auxiliam no processo de ensino e de aprendizagem:

\begin{abstract}
Interação multidirecional e multimodal, conexões possíveis de se estabelecer com links internos ou externos aos sistemas, o registro contínuo das produções que podem integrar múltiplas mídias e dos caminhos percorridos pelo aluno ao explorar informações por meio da navegação alinear, a recuperação instantânea dos registros de qualquer etapa do processo, realização de tantas atualizações quantas forem necessárias, a avaliação da aprendizagem do aluno e do projeto do curso (ALMEIDA, 2010, p. 92).
\end{abstract}

Para a concepção da plataforma ANP.Net foram analisados vários modelos existentes ao redor do mundo, tendo a Academia Nacional de Polícia optado pelo modelo Moodle. Conforme a literatura o Modular Object-Oriented Dynamic Learning Environment Moodle é um software livre e gratuito, que pode sofrer modificações. Este programa vem sendo utilizado por diversas instituições no mundo, possuindo uma grande comunidade de membros que se dedicam à correção de possíveis erros existentes e para o desenvolvimento de novas funcionalidades a serem aplicadas nos processos de ensinoaprendizagem.

Os recursos encontrados neste modelo são: disponibilização de conteúdos em vários formatos de arquivos, avaliação de curso, chat, diálogo, fórum, glossário, lição, pesquisa de opinião, questionário, tarefas, trabalho com revisão e a ferramenta wiki (para produção intelectual do grupo).

Os marcos legais da EaD no Brasil foram estabelecidos pela Lei de Diretrizes e Bases da Educação Nacional - LDB (Lei n 9.394/1996), pela Portaria MEC n 301/1998 e, por último, o Decreto $n^{\circ} 5622 / 2005$, que regulamentou todas as possibilidades de modalidades educacionais, utilizando os ambientes virtuais de aprendizagem.

Os marcos normativos da EaD na Polícia Federal foram estabelecidos pelas Instruções Normativas no 016/2005-DG/DPF e n 10/2007-DG/DPF, que regulamentaram as ações de educação a distância implementadas pela Academia Nacional de Polícia, universidade corporativa da instituição. A plataforma ANP.Net foi concebida em 2007 e disponibilizada ao público em 2008, sendo, atualmente, 1 (uma) das 3 (três) plataformas distintas oferecidas atualmente pelo Serviço de capacitação e educação à distância SECAED/ANP/DGP/PF:

- ANP.Net: dedicada aos servidores do órgão.

- ANP.Cidadão: dedicada ao público externo.

- ANP-PF/SESGE-MJ: dedicada aos servidores do órgão recrutados para atuarem nos Jogos Olímpicos Rio 2016 e Jogos Paralímpicos Rio 2016.

A plataforma ANP.Net oferece os seguintes serviços: Comunidades Temáticas, Comunidades de Gestão, Cursos de Pós-Graduação, Cursos de aperfeiçoamento para progressão funcional e Cursos de aperfeiçoamento contínuo, conforme figura abaixo: 


\section{Figura 1 - Serviços oferecidos na plataforma ANP.Net}

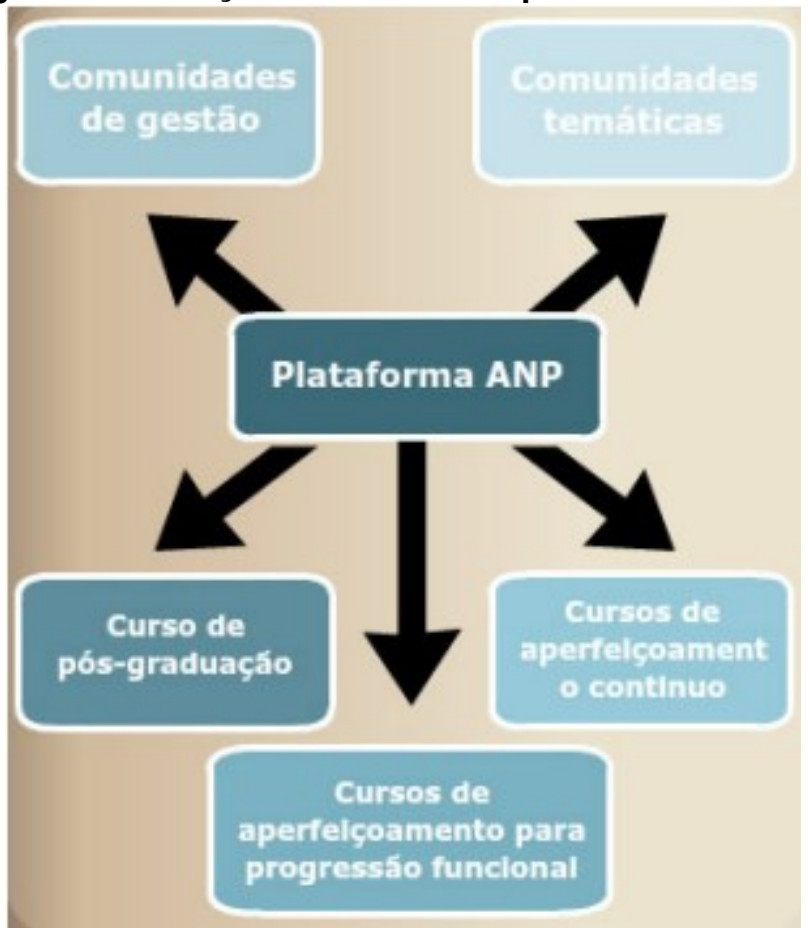

Fonte: https://ead.dpf.gov.br

As comunidades temáticas consistem em um espaço destinado a promoção de debates técnicos com diversos especialistas sobre um determinado tema, a exemplo: crimes cibernéticos, segurança privada, controle migratório, etc.

As comunidades de gestão consistem em um espaço destinado a promoção de debates de gestores de setores específicos, a exemplo: Setores de perícia, Delegacias especializadas, Setores de logística, etc.

Os cursos de pós-graduação são aqueles ofertados para os servidores policias nas áreas de documentoscopia, gestão da investigação criminal, inteligência policial.

Os cursos de aperfeiçoamento para progressão funcional são aqueles ofertados para os servidores policiais voltados à progressão na carreira.

Os cursos de aperfeiçoamento contínuo são aqueles ofertados para os servidores relacionados ao desenvolvimento do órgão e destinados à formação contínua do servidor. Está previsto no Plano Anual de Capacitação - PAC relativo ao ano de 2016 a execução de 369 (trezentas e sessenta e nove) ações de capacitação, dentre as quais, 96 (noventa e seis) cursos de aperfeiçoamento contínuo no ambiente ANP.Net. O gráfico abaixo descreve a relação existente entre cursos de capacitação continua promovidos nas modalidades presencial e EaD. 
Gráfico 1 - Previsão de ações da Capacitação na ANP.

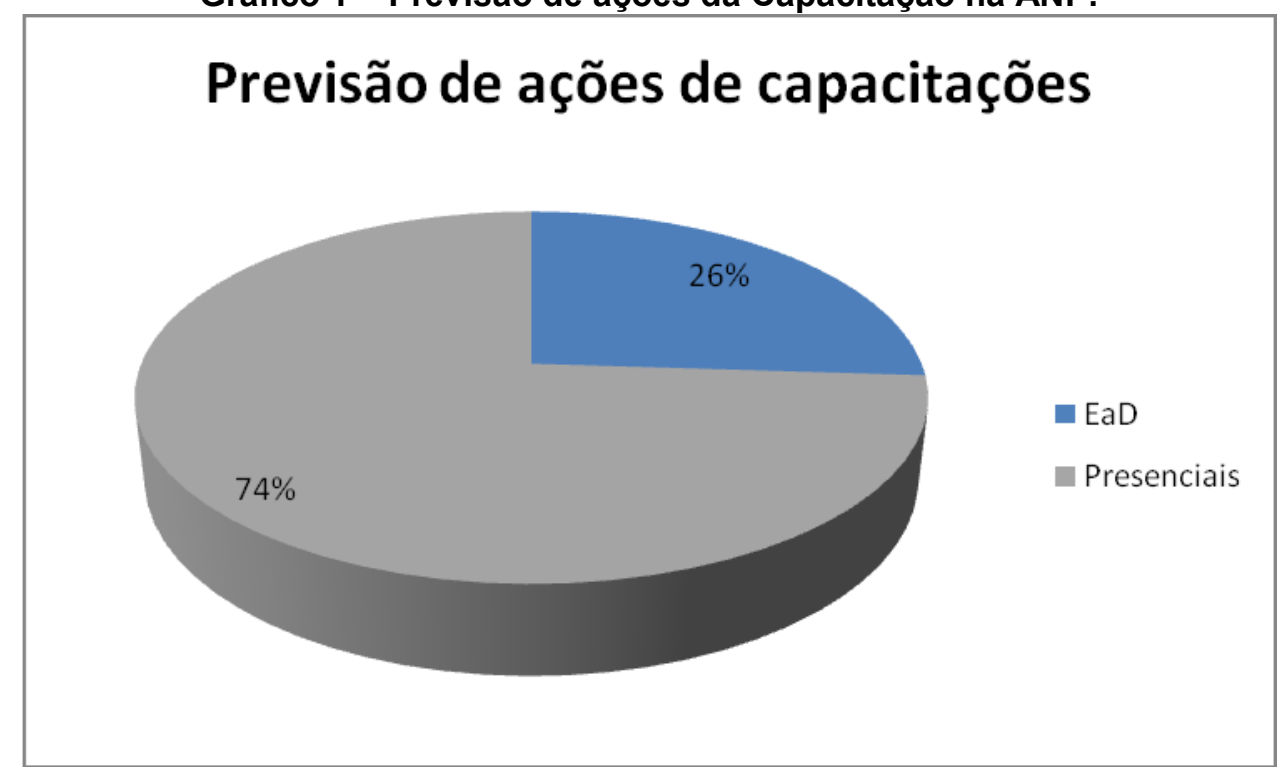

Fonte: PAC 2016 (Portaria nº 2239/2015-DGP/DPF).

Os tutores da ANP.Net atuam nos cursos de pós-graduação, aperfeiçoamento da carreira policial federal e nos cursos de aperfeiçoamento contínuo. O regime escolar da Academia Nacional de Polícia prevê o agrupamento das ações de capacitação por trimestres, nos quais muitas dessas ocorrem em todos os períodos.

Neste artigo nos limitaremos a discorrer apenas sobre os cursos de aperfeiçoamento contínuo tendo em vista o curso de formação de tutores estar inserido no rol dos cursos promovidos nesta modalidade.

\section{DESENVOLVIMENTO}

O curso de formação de tutores na ANP.Net foi estruturado em 4 (quatro) semanas, perfazendo uma carga horária de 60 (sessenta) horas-aula de atividades na plataforma. A participação neste curso é um pré-requisito básico para a atividade de tutoria de cursos, modalidade à distância, ofertados pela Academia Nacional de Polícia.

Neste curso foram abordados os aspectos fundamentais do processo ensinoaprendizagem, a educação, educação a distância, tutoria, papéis do tutor, processo de planejamento e elaboração de um curso, os documentos de tutoria e uma simulação detalhada das atividades do tutor no ambiente virtual de aprendizagem da Polícia Federal.

A mediação do curso foi realizada totalmente a distância, através da plataforma ANP.Net com utilização de tutor. Utilizou-se de cenários, textos de conteúdo e materiais complementares, tarefas, estudos de casos, salas de bate-papo, fóruns de discussão temática e de interação e uma atividade de simulação de tutoria em cursos EaD da Academia Nacional de Polícia. 
Figura 1 - Página do Curso de Formação de Tutores da ANP.Net

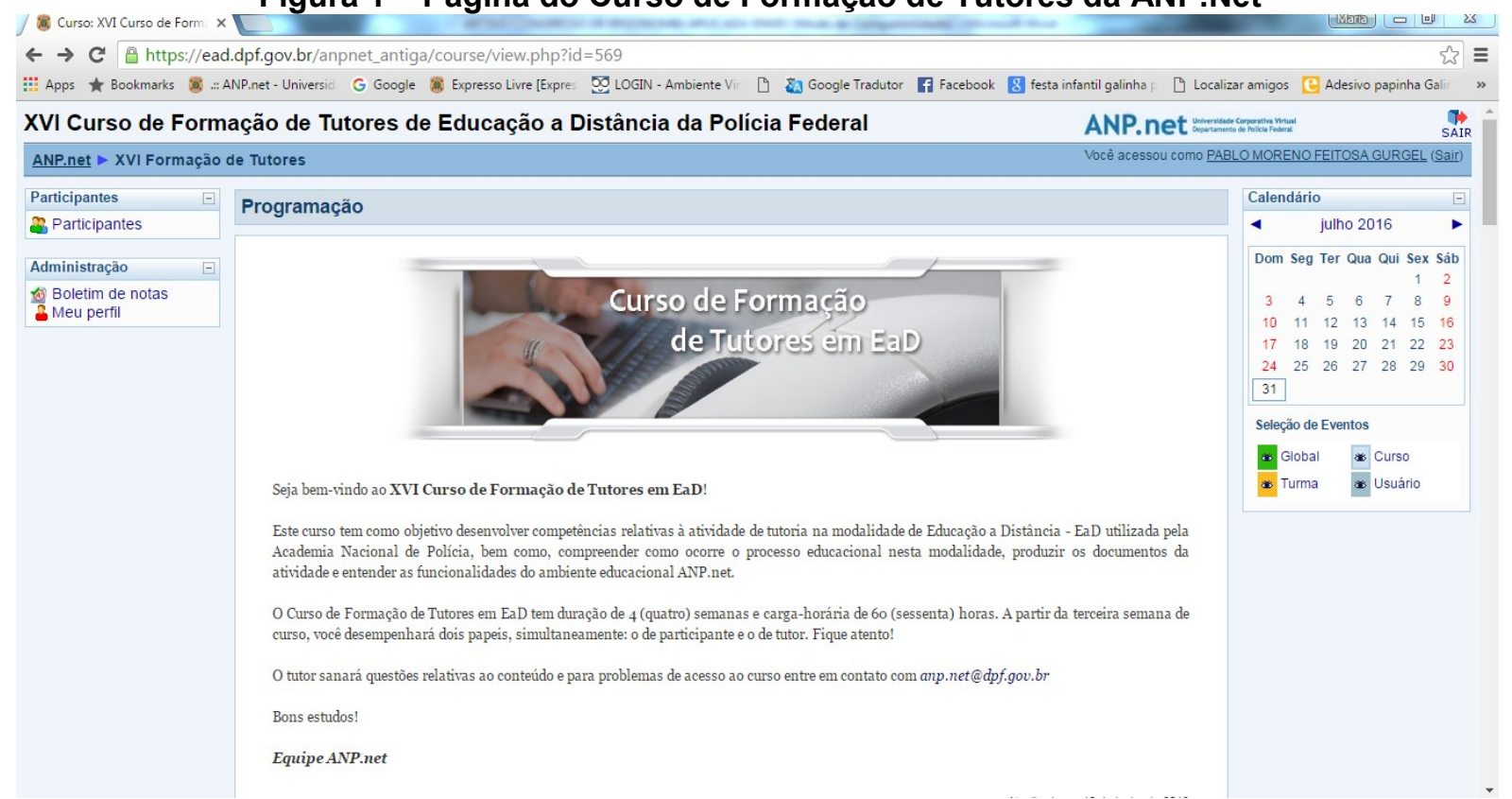

Fonte: https://ead.dpf.gov.br

Conforme ambientação da plataforma a página inicial foi estruturada em 3 (três) colunas. A coluna da esquerda trás as informações participantes, boletim de notas e perfil. A coluna central trás informações sobre a programação do curso, bem como links de documentos, atividades do curso (fóruns, chats, tarefas, pesquisas, avaliações, etc), áudios, animações, vídeos. A coluna da direita possui informações do calendário do curso, datas de início e término do curso.

O curso foi idealizado com 3 (três) unidades. A Unidade I abordou os conceitos de educação, educação à distância, ambientes virtuais de aprendizagem, conceitos e especificidades sobre a atividade da tutoria. Os recursos utilizados para o cumprimento da Unidade I do curso foram os constantes da Orientação de Estudo, conforme a Figura 2 abaixo:

\section{Figura 2 - Orientação de estudo unidade I}

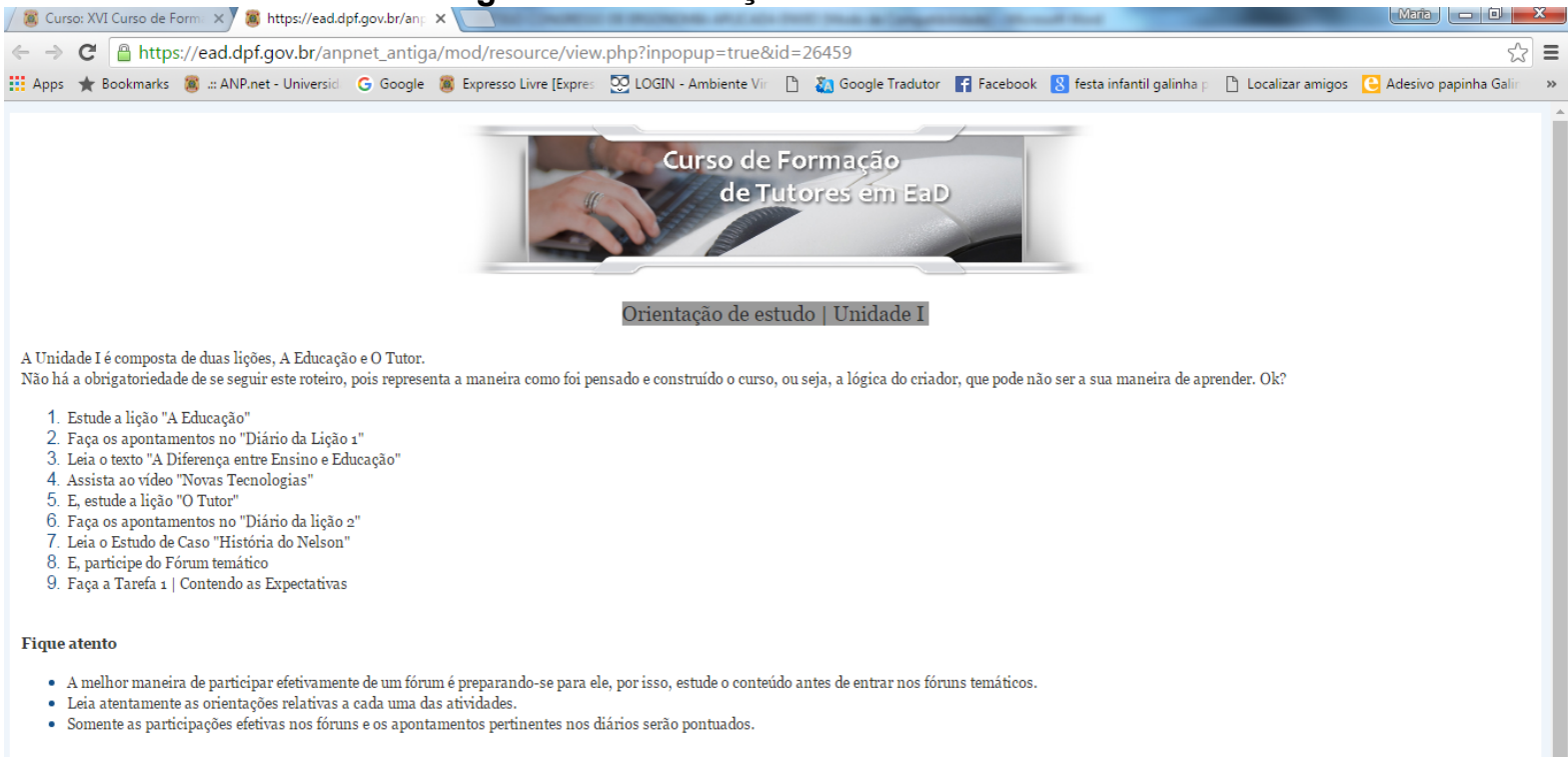

Fonte: https://ead.dpf.gov.br 
Nos itens constantes da Orientação pudemos observar os recursos:

- Apresentação de animação hipermídia do conteúdo em linguagens HTML, Flash e PHP, ou seja, em visualizador digital de conteúdo, no qual o aluno tinha acesso a todo o conteúdo da unidade.

- Apontamentos em diários, nos quais o aluno necessitava discorrer sobre assuntos abordados na unidade.

- Apresentação de texto em extensão PDF.

- Apresentação de vídeos relacionados aos conteúdos e aos objetivos.

- Fórum temático, de interação assíncrona, para discussão do conteúdo da unidade.

- Tarefa avaliativa.

A Unidade II do curso abordou a estruturação de um curso a distância: conteúdo, desenho instrucional, programação web, plano de tutoria e modelos de mensagens do tutor para os alunos. Os recursos utilizados para o cumprimento da Unidade II do curso foram os constantes da Orientação de Estudo, conforme a Figura 3 abaixo:

Figura 3 - Orientação de estudo unidade II

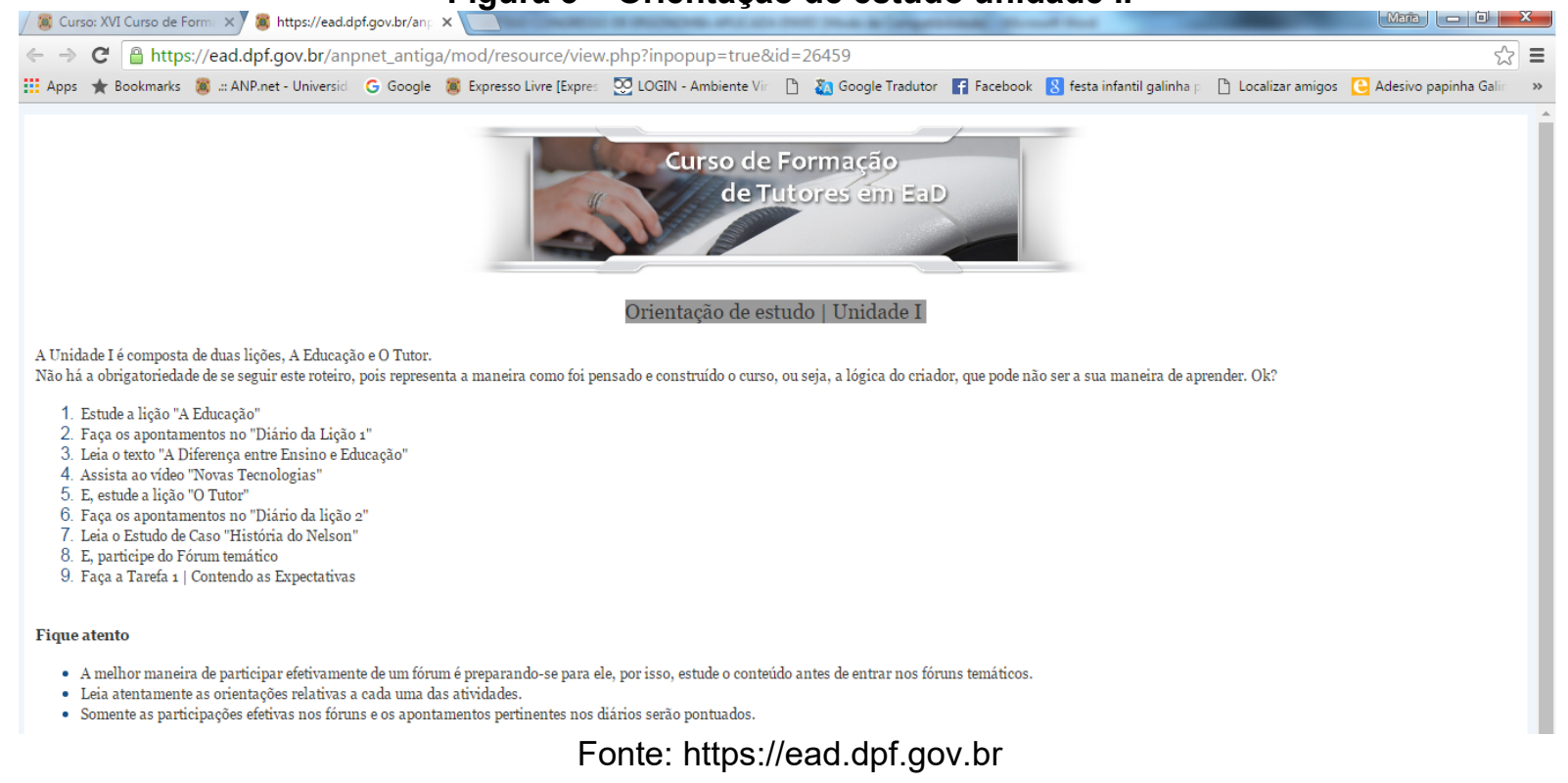

Nos itens constantes da Orientação pudemos observar os recursos:

- Apresentação de animação hipermídia do conteúdo em linguagens HTML, Flash e PHP, ou seja, em visualizador digital de conteúdo, no qual o aluno tinha acesso a todo o conteúdo da unidade.

- Apresentação de textos em extensão PDF.

- Apontamentos em diário, nos quais o aluno necessitava discorrer sobre assuntos abordados na unidade.

- Apontamentos em enquete.

- Apresentação de vídeos relacionados aos conteúdos e aos objetivos.

- Fórum temático, de interação assíncrona.

- Tarefas avaliativas, dentre as quais a construção de um plano de tutoria.

- Chat para discussão de conteúdos.

A Unidade III do curso foi destinada à realização de algumas atividades do curso, bem como da simulação de uma tutoria no curso Ética na Atividade Policial na plataforma ANP.Net. Nesta simulação o tutor acompanhou 3 (três) alunos virtuais com perfis distintos entre si, devendo estimulá-los a realizarem as tarefas do curso, bem como orientálos em suas contribuições. Os recursos utilizados para o cumprimento da Unidade III do curso foram os constantes da Orientação de Estudo, conforme a Figura 4 abaixo: 
Figura 4 - Orientação de estudo unidade III

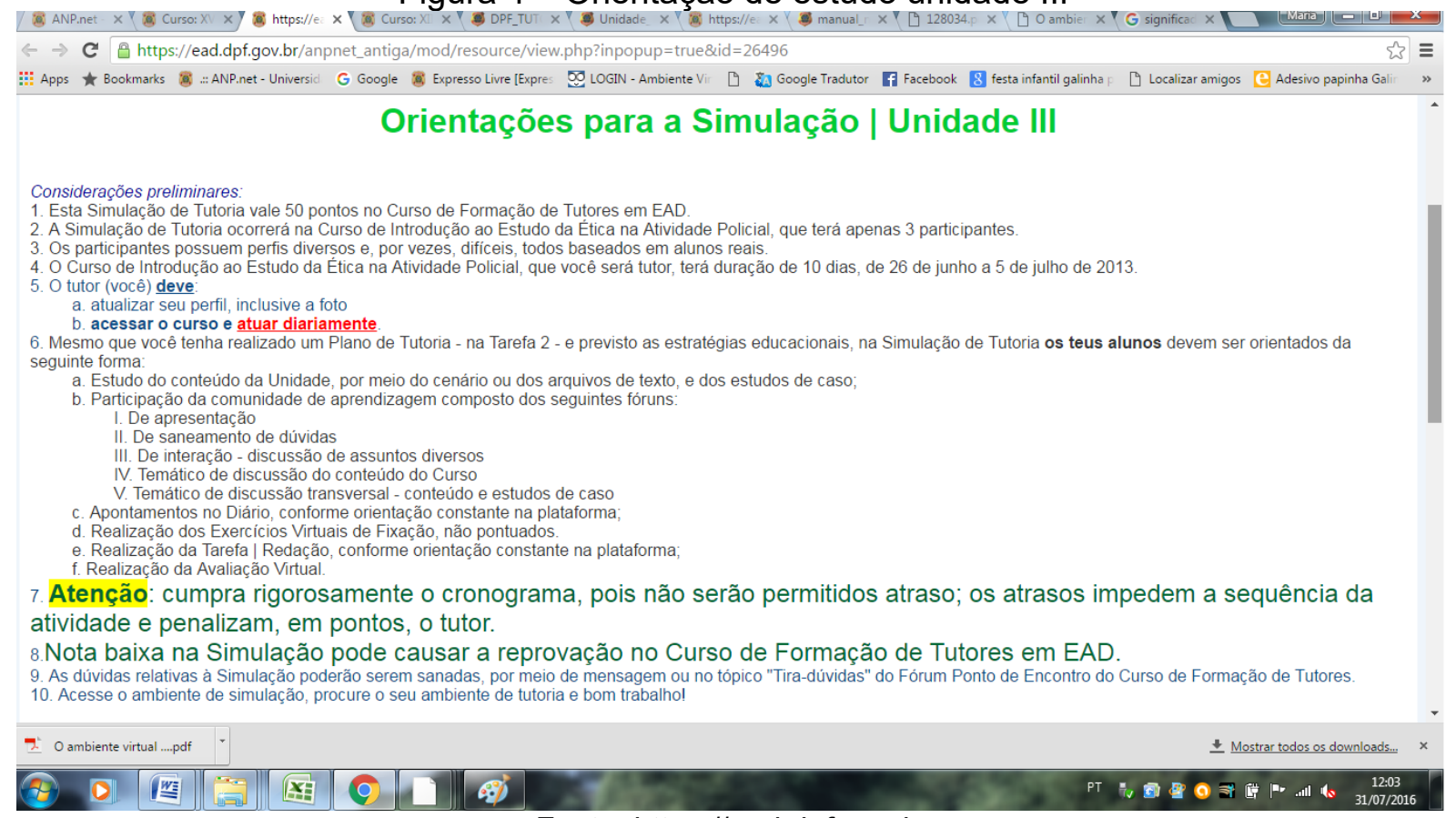

Fonte: https://ead.dpf.gov.br

Nos itens constantes da Orientação pudemos observar os recursos:

- Apresentação de animação hipermídia do conteúdo em linguagens HTML, Flash e PHP, ou seja, em visualizador digital de conteúdo.

- Link para simulação de tutoria.

- Apresentação de textos em extensão PDF.

- Apontamentos em diário.

- Apontamentos em enquetes.

- Tarefa avaliativa.

- Fórum temático, de interação assíncrona.

- Tarefas avaliativas.

\section{CONCLUSÃO}

Os ambientes virtuais de aprendizagem são mídias que permitem a interação de vários atores, que estão intrinsecamente envolvidos nos processos de ensinoaprendizagem das ações educacionais existentes. Para o alcance de seus objetivos os tutores desenvolvem inúmeras tarefas ao longo dos cursos que vão desde a construção do plano de tutoria, manuseio adequado das ferramentas disponíveis na plataforma, acompanhamento do acesso dos alunos, mediação das discussões de conteúdos, motivação dos participantes, dentre outras afetas à função a que se propõe.

Neste caso entende-se que a tutoria não possui um modelo único de intervenção; ela depende de cada realidade distinta. Em EaD o papel do tutor é fundado na necessidade do contato humano. Em particular, o processo de ensino-aprendizagem exige sua existência. Ela viabiliza uma educação individualizada e cooperativa na qual o tutor assume o papel de orientador do aluno, colocando os recursos que possibilitam um estudo de forma autônomo, para entender aos objetivos do curso. O tutor necessita desenvolver habilidades e comportamentos que tornarão competente na função a ser desempenhada (COSTA, PARAGUAÇU e PINTO, 2009, p. 122).

O curso de formação de tutores da ANP.Net foi estruturado de forma que o aluno pudesse se familiarizar com os conceitos da educação à distância, planejamento educacional, reconhecer as potencialidades da plataforma e saber operacionalizar aquele 
ambiente virtual nos perfis de aluno e de tutor. Os recursos existentes são muito bem explorados e eficazes para a interação dos participantes e para o que o ambiente virtual se propõe: ser eficaz no processo ensino-aprendizagem.

\section{REFERÊNCIAS BIBLIOGRÁFICAS}

Academia Nacional de Polícia. Curso de Formação de Tutores de Educação a Distância da Polícia Federal. Brasília, 2013. (Apostila do Curso de Formação de Tutores de Educação a Distância da Polícia Federal - Academia Nacional de Polícia).

ALMEIDA, Maria Elizabeth Bianconcini. Currículo, avaliação e acompanhamento na educação a distância. In: MILL, Daniel Ribeiro Silva; PIMENTEL, Nara Maria (Org.). Educação a distância: desafios contemporâneos. São Carlos: EDUFSCar, 2010.

BRASIL. Lei $n^{\circ} 9.394$ de 20 de dezembro de 1996. Estabelece as diretrizes e bases da educação nacional. Brasília, 1996. Disponível em: http://www.planalto.gov.br/ccivil 03/leis/L9394.htm. Acesso em 20 jun 2016.

BRASIL. Ministério da Educação e do Desporto. Portaria n 301 de 07 de abril de 1998. Dispõe sobre o credenciamento de instituições de ensino para o ensino a distância. Brasília, 1998. Disponível em: http://portal.mec.gov.br/seed/arquivos/pdf/tvescola/leis/port301.pdf. Acesso em 21 jun 2016.

BRASIL. Decreto $n^{\circ} 5.622$ de 19 de dezembro de 2005. Regulamenta o art. 80 da Lei no 9.394, de 20 de dezembro de 1996, que estabelece as diretrizes e bases da educação nacional. Brasília, 2005. Disponível em: http://www.planalto.gov.br/ccivil 03/ ato20042006/2005/decreto/d5622.htm. Acesso em 21 jun 2016.

BRASIL. Ministério da Justiça. Polícia Federal. Instrução Normativa no. 016/2005-DG/DPF, de 29 de julho de 2005. Determina que as atividades referentes aos cursos realizados a distância e respectiva retribuição pecuniária sejam regulamentadas em normativo próprio.

BRASIL. Ministério da Justiça. Polícia Federal. Instrução Normativa n¹0/2007-DG/DPF de 08 de junho de 2007. Regulamenta as ações de educação a distância implementadas pela Academia Nacional de Polícia e respectiva retribuição pelo exercício de encargos de atividades desta modalidade.

BRASIL. Ministério da Justiça. Polícia Federal. Portaria n².239/2015-DGP/DPF de 02 de dezembro de 2015. Plano Anual de Capacitação de 2016.

COSTA, Cleide Jane de Sa Araujo Costa; PARAGUAÇU, Fabio; PINTO, Anamelea de Campos. Experiências interativas com ferramentas midiáticas na tutoria on-line. In: MERCADO, Luis Paulo Leopoldo (org.). Em aberto: Integração de mídias nos espaços de aprendizagem. n. 79, Brasília: INEP, 2009. 